\title{
La espectacularización de la naturaleza: estudio de la serie documental Seaway
}

Fátima Gil Gascón | fatimagg@ubu.es

Fernando Melgosa Rodríguez | fmelgosa@ubu.es

UNIVERSIDAD DE BURGOS

Resumen: Este artículo tiene como objetivo examinar la forma en la que los documentales de naturaleza participan de la progresiva espectacularización de los formatos televisivos a través del estudio de Seaway (González y Rodríguez, 2014), una serie documental española de 13 capítulos sobre el mundo submarino. Para ello se ha procedido al análisis cuantitativo y cualitativo de las herramientas visuales, narrativas y sonoras usadas por este tipo de productos para atraer y seducir al espectador. El estudio de estas cuestiones ha permitido constatar la presencia de las formulas tradicionales así como descubrir las nuevas tendencias utilizadas por el lenguaje documental para plasmar el mundo marino de forma amena y atractiva tal y como exigen los nuevos cánones televisivos.

Palabras clave: documental de naturales, espectacularización, Seaway

Abstract: This article aims to examine how documentaries on nature participate in the progressive "showization" of television formats through the study of "Seaway" (Gonzalez y Rodriguez, 2014), - a Spanish 13-chapters documentary series about the underwater world. To this end, we proceeded to the quantitative and quality analysis of those visual, narrative and sound tools that these products use to attract and charm the audience. The study of these questions allowed us to verify the presence of traditional formula, as well as to uncover those new tendencies that the documentary language uses to embody the underwater world in an entertaining and engaging way - just as required by the new television standards

Key words: documentaries on nature, showization, Seaway 


\section{Introducción}

El espectáculo es necesario para la sociedad. Esta afirmación, aunque puede resultar algo pretenciosa, se sustenta en que desde hace siglos el ser humano necesita experimentar, provocar o seducir a los demás.

A pesar de esto, en las últimas dos décadas el espectáculo en los medios de comunicación es un mecanismo que se utiliza $y$, en algunos casos, se manipula para transformar 0 estigmatizar cualquier producción audiovisual. Así, hablar de espectacularización en la televisión conlleva una acusación de pérdida de valores o incluso de banalización del medio.

Es necesario, por lo tanto, diferenciar la naturaleza espectacular que podemos encontrar en cualquier programa y que no debería contener ningún carácter negativo frente a la queja de la espectacularización como degeneración en los distintos programas de televisión.

Seducir, cautivar, fascinar... revelan procesos en los que el deseo del telespectador y su capacidad de reflexión y de análisis quedan empañados en gran medida. El telespectador que es seducido por el espectáculo televisivo se abandona con satisfacción ante aquello que está viendo y que atrae su interés. Además, proyecta sus deseos y sus ansias de satisfacción. En la seducción televisiva, la racionalidad se sustituye por la emotividad y los contenidos y la función referencial son relegados a un segundo plano por el propio proceso de comunicación que se ritualiza.

La seducción es profundamente ambivalente porque reúne en una misma relación tanto la belleza como la monstruosidad o lo positivo como lo negativo; por ello, algunos géneros televisivos, cuyos contenidos a priori resultan menos espectaculares como pueden ser los documentales, son objeto de un tratamiento heterodoxo que arrastra hacia la espectacularización.

Frente a otro tipo de formatos de no ficción, los documentales de naturaleza son uno de los géneros televisivos más populares y de mayor desarrollo en los últimos años. Aunque, las nuevas tecnologías han introducido variedades sustanciales a la hora de mostrar visualmente la cotidianeidad de los seres vivos -buena prueba de ello es la serie sobre dinosaurios emitida por la BBC que mostraba al espectador, gracias a la realidad virtual, la vida de estos grandes animales extintos virtual (Scott, 2006, 131-152)-, las fórmulas propias del formato han continuado casi inalterables desde que en los años cuarenta Walt Disney introdujera el concepto de espectáculo en sus planteamientos visuales y narrativos. Además de establecer los parámetros representativos de este tipo de programas -basados en la antropomorfización, la subjetividad a la hora de abordar y narrar diversos temas o la construcción de las acciones en clave de ficción- Disney favoreció la sensibilización de los espectadores sobre los problemas de la naturaleza y contribuyó a crear interés por este tipo de productos (King, 1996, 60-69). 
En los años sesenta, National Geographic y la BBC comenzaron a realizar sus primeras series documentales que, si bien mantenían los principios establecidos por el realizador norteamericano, esbozaban una mayor rigurosidad en sus planteamientos.

Dentro de este tipo de formatos se desarrollaron algunos productos centrados en determinados profesionales como Jacques Cousteau, David Attemborought o Félix Rodríguez de la Fuente, quienes, con sus conocimientos y carisma, buscaron una representación realista de la naturaleza pero sin abandonar las técnicas de filmación y montaje propias de la ficción (Cabeza y Mateos, 2023, 570-583).

Conocidos como Blue chip documentary, este género, vigente todavía en la actualidad, tiene una serie de convenciones centradas, principalmente en la elección de animales singulares y en la obtención de imágenes impactantes de gran calidad. La acción dramática se centra en los seres vivos obviando referencias políticas o históricas así como cualquier presencia humana salvo la de las tribus o pobladores autóctonos. Aunque no hay un planteamiento científico explícito, a estos formatos se les presupone una cierta tendencia academicista (Bagust, 2008, 213-226).

Frente a la aparente objetividad fundada en la observación activa propia de estos productos, algunos autores señalan la existencia de un subgénero de este tipo de formato, que deliberadamente interpondría al ser humano entre el espectador y la naturaleza como un presentador-explorador de una realidad remota y ajena (Scott, 2002, 60-68).

Es el caso de la serie documental Seaway que participa de la tendencia actual que impone el entretenimiento como modelo comunicativo sin prescindir de la función social y de transmisión de conocimiento. Ésto puede verse en la vigente necesidad de la pequeña pantalla de ser vehículo de trasmisión de modelos y pautas de comportamiento, en este caso, ecológicos y de medio ambiente. La principal función de Seaway es entretener, pero relegando los elementos de espectacularización que empleados por la televisión principalmente ocupar y divertir- y potenciando los mecanismos visuales y sonoros que permiten seducir o fascinar, $y$, especialmente, persuadir al espectador.

\section{Metodología y fuentes}

Este artículo tiene como objetivo examinar las fórmulas de espectacularización utilizadas por la serie documental Seaway (González y Rodríguez, 2014). Para ello se ha procedido al análisis cuantitativo y cualitativo de las herramientas de contenido, visuales y sonoras presentes en cada uno de los episodios del programa.

Este formato producido por Takeway Films está compuesto de trece capítulos y fue emitido por el segundo canal de televisión española en el verano del 2014. Tiene una trayectoria internacional -ha sido emitido en EEUU y en Rusia así como en los vuelos transoceánicos de Aireuropa- y ha sido premiado en festivales como San Sebastián o Belgrado. 
El estudio de los capítulos se ha realizado abordando los diversos instrumentos que conforman el relato secuencial. En relación a los planos sonoros y visuales, y siguiendo el modelo de análisis establecido por Jacques Aumont y Michel Marie, se ha atendido a los siguientes parámetros (Aumont y Marie, 1988, 58):

- Duración de los planos y número de fotogramas

- Escala de los planos, presencia y movimientos de personas y/u objetos en el campo

- Montaje: tipos de raccords, puntuaciones...

- Banda sonora: comentarios, indicaciones de la música, efectos sonoros, escalas sonoras... relación de la imagen y el sonido.

Puesto que la premisa de que la parte la investigación es el estudio de los elementos de espectacularización utilizados por la serie documental, narrativamente se ha atendido a aquellas cuestiones que, de alguna manera ayudan a potenciar estas cuestiones: tipos de animales escogidos, focalización de la historia, temas abordados, reflexiones sobre el entorno visitado, tono predominante en el relato... El análisis de estas cuestiones permitirá descubrir la forma en la que estos documentales plasman la vida natural y en qué medida participan en el proceso de espectacularización propio de la actual televisión.

\section{Análisis Narrativo}

Seaway consta de trece episodios, once de los cuáles fueron grabados en territorios internacionalmente conocidos por su riqueza marina: Cuba, México, Panamá, Indonesia, Papúa Nueva Guinea, Islas Canarias, Islas Fiji, Malasia, Costa Rica, Australia y Micronesia. Estas zonas fueron escogidas tanto por su enorme biodiversidad como por ser lugares aparentemente inhóspitos y poco frecuentados.

Sobre ambas cuestiones, la presencia de muchas especies diferentes y poco comunes y la búsqueda de la novedad a través de lugares poco explorados, descansa todo el peso narrativo de la acción. Estas no solo vertebran y justifican el contenido visual sino que, además, dotan a la serie de una cierta singularidad y espectacularidad. Las tierras escogidas son descritas como lugares bellos y mágicos. Es el caso de Malasia (Capítulo $8^{\circ}$ ) cuyas playas «nos permiten confirmar que estamos en un escenario de cine» o de Indonesia (Capítulo $4^{\circ}$ ) cuyo «colores son un derroche de belleza para los sentidos». Otra cuestión que se destaca es su condición de tierras salvajes, alejadas e inaccesibles tal y como se muestra en el capítulo $6^{\circ}$ sobre las islas canarias ("Hoy la vida ha cambiado mucho pero este pueblo conserva el sabor de los lugares alejados del mundo") o en el dedicado a Papúa Nueva Guinea (capítulo 50) que "aún está al margen de los circuitos que han conectado todo". 
Estos territorios son interesantes para el espectador porque le son extrañas y desconocidas y le permiten acceder a lugares y situaciones completamente ajenos a su devenir cotidiano. La singularidad de las imágenes se señala aludiendo a la dificultad de acceso que el ser humano tiene a algunas especies. Un ejemplo es el Quetzal de quien se dice "Observarlo es un sueño que persigue todo naturista aunque cada día es más difícil porque se extingue de un modo alarmante" (Costa Rica, capítulo 90)

Los dos últimos capítulos suponen una reorganización y reestructuración geográfica del material ya visto. Estos resúmenes incorporan, como única novedad, la presencia de los realizadores de la serie quienes introducen las diversas zonas comentando algunas de las cuestiones más relevantes sobre las mismas.

Siguiendo la tendencia de algunos documentales de naturaleza que tratan también la interacción del ser humano con el medio (Scott, 2003, 131), Seaway aborda el conocimiento de los fondos marinos a través de diversas expediciones de buceo. Esta actividad y todo lo que ella conlleva no solo es el leitmotiv de la serie, también es la auténtica protagonista (Bienvenido, 2001, 253-266). Lejos de profundizar en las características de los ecosistemas visitados, la mayor parte de los capítulos abordan el territorio de una forma trivial entremezclando, como si estos elementos tuvieran la misma trascendencia, la riqueza marítima de las costas con los hoteles o resort más importantes o los lugares turísticos más emblemáticos de la zona. Esta amalgama de intereses convierte a la serie en un formato híbrido que aúna elementos de dos tipologías diferentes: los documentales de naturaleza y los de viajes.

Los capítulos no presentan pautas formales uniformes ni en el orden que ocupan dentro de la serie, que no parece responder a una estructura preestablecida, ni en el planteamiento o las herramientas utilizadas. El comienzo de los documentales sigue el mismo patrón: una breve introducción del lugar y una cabecera que dan paso a la presentación de la zona y del recorrido a seguir. Sin embargo, tanto el contenido como, principalmente el final del capítulo, parece adecuarse más a la idiosincrasia de los fondos marinos que a una formula preestablecida.

Los seis primeros episodios -Cuba, México, Panamá, Indonesia, Papúa Nueva Guinea y Canarias- tienen una estructura circular enfatizada por el uso simbólico de la luz solar. Estos comienzan llegando a la zona de día y termina alejándose físicamente de la misma mientras anochece. Los planos finales, grabados desde una lancha, muestran cómo ésta se aleja del territorio visitado. La $v o z$ en off señala la llegada y se despide del lugar señalando las características positivas del mismo: "nos ha cargado de energía y pura naturaleza" (Cuba, capítulo $1^{\circ}$ ), "termina un viaje que nos llevó por rutas desconocidas" (México, capítulo $2^{\circ}$ )...

Los cinco últimos capítulos no presentan este uso metafórico de la luz ni plantean la despedida visualmente aunque sí se mantiene la valoración final transmitida por la narradora. 
Los documentales están narrados por una voz femenina que pertenece a la realizadora del documental quien, en primera persona del plural, refiere los acontecimientos al espectador. Frente a los documentales marinos tradicionales en los que el narrador adopta una postura objetiva y distante, la locución, unida a la constante presencia visual de la directora, manifiestan una clara focalización ${ }^{1}$ de lo acaecido a través de sus reflexiones y sus valoraciones. Esto puede observarse en el marcado carácter eurocentrista de sus apreciaciones que califican la naturaleza de estas zonas como "salvaje y sorprendente" (Cuba, capítulo $1^{\circ}$ ), "paradisíaca" (Panamá, capítulo $3^{\circ}$ ), "virgen y desconocida" (Indonesia, capítulo 40), e incluso "olvidada" (Papúa Nueva Guinea, capítulo 50),

Aunque su objeto de interés es la vida existente en los fondos marinos Seaway no aborda su estudio de una forma rigurosa, ni se ofrecen datos relevantes sobre su modo de vida o sobre su interacción con el ecosistema. La finalidad de los datos aportados que, por lo general, revelan curiosidad sobre los animales -muchas de las cuáles son sobre sus modos de reproducción- es básicamente el entretenimiento y la sorpresa.

Los peces, tortugas y demás seres que pueblan las aguas marinas son abordados en relación no a su propia existencia sino a su posible interés para el ser humano. La percepción selectiva, la antropomorfización (Salcedo, 2009, 217-246) o la mezcla entre seres salvajes y amigables son algunas de las herramientas utilizadas para crear un mundo marino atrayente (King, 1998, 60-68).

Esto puede verse en la propia elección de las especies, basada, principalmente, en la excepcionalidad de las mismas, ya sea por su muy concreta localización o por su llamativo aspecto. Puesto que estos documentales pretenden adentrarse en las principales reservas marinas del planeta, el foco de atención se pone sobre las especies endémicas, propias de cada zona como la jumilla en Cuba (Cuba, capítulo $1^{\circ}$ ), o el caballito pigmeo en Papúa Nueva Guinea (Papúa Nueva Guinea, capítulo 5º).

La rareza de sus formas o colores es uno de los principales elementos que se señalan así como su gran o pequeño tamaño en relación al ser humano. Es el caso del tiburón ballena, "el pez más grande que existe" que, aunque, puede llegar a medir unos cuatro metros de longitud es inofensivo (Costa Rica, capítulo 90).

Junto a las especies sorprendentes, aparecen también algunos peces más comunes y reconocibles como los tiburones o los peces payaso. Pese al manifiesto deseo de alejarse de los estereotipos hollywoodienses, la serie documental ayuda a perpetuar las ideas sobre los unos y los otros. No en vano, se alude en varias ocasiones a la posible fiereza de los tiburones - Aparecen tiburones en los capítulos: 10, 30, 50,70, 80, 90, 100, 110- mostrando, además, dos escenas de comida así como a la simpatía del pez payaso (capítulos 40, 50, 80,

\footnotetext{
${ }^{1}$ Se entiende que un relato se focaliza en torno a un personaje cuando en torno a él se concentran todos los elementos de la historia convirtiéndolo en un centro de equilibrio que acaba erigiéndose como foco de atención. (Casetti y Di Chio, 1991, 157)
} 
$10^{\circ}$ y $11^{\circ}$ ) que vive entre las anémonas. Fieros y divertidos son las especies que más aparecen en estos documentales.

La serie presenta un tono poético, alejado de las pretensiones divulgativas de algunos de estos formatos. Esto se observa principalmente en dos cuestiones. Por un lado, este planteamiento idealiza completamente la naturaleza y las experiencias vividas alejándose radicalmente de la realidad. La continua utilización de adjetivos que califican positivamente lugares y animales remite a la creación de un mensaje agradable que únicamente se rompe al hablar de la extinción de las especies y la destrucción de los ecosistemas.

Por otro lado, la valoración lírica de las actitudes de los animales descodificar sus comportamientos haciéndolos legibles al espectador al humanizar sus actitudes. Los peces unicornio, que pueblan las aguas australianas, son calificados de "tímidos" lo que ocasiona que vayan en grupo y "se hagan compañía" (Australia, capítulo 100) frente a ellos, las pagas que habitan las mismas aguas "son muy curiosas y se acercan a nosotros son ningún problema".

Frente a otros documentales de este tipo, en Seaway apenas aparecen planos en donde se muestre a la fauna marina cazando, comiendo o reproduciéndose; actos muy recurrentes a la dramatización. Las pocas imágenes dramatizadas son inmersiones nocturnas o bucear entre tiburones viendo como les dan de comer a pocos metros y en donde la emoción es generada principalmente por el gerente de la empresa que organiza estas inmersiones: "Para que mantengan el interés movemos un poco el cubo alrededor del anfiteatro y, así, los buceadores pueden verlos en primer plano" (Australia, capítulo 10). También se observa cierta dramatización al bucear contracorriente en el Blue Corner atados; o en la Cueva de las tortugas con cientos de esqueletos donde, para redundar en el acto peligroso, se vuelve a reproducir la imagen del cartel que hay a la entrada de dicha cueva: una calavera con dos fémures cruzados y la frase iPeligro de muerte!. La coprotagonista subraya esta sensación comunicando con su lenguaje corporal el temor a entrar en esta cueva, en una de las escenas más largas de toda la serie (Capítulo 8. De 10'30" a 17' 25"). Igualmente se advierte dramatización en los volcanes submarinos activos o las historias de duendes o con personajes de los distintos lugares...

Con todo, estas dramatizaciones no superan los 40 minutos de los 340 que dura Seaway; es decir, un 8 '5\% del tiempo de emisión de la serie, por lo que se puede afirmar que éstas no son un soporte narrativo prioritario.

\section{Análisis visual y sonoro}

Las imágenes espectaculares son el punto fuerte de esta serie documental, que muestra vistas de gran calidad y de una enorme belleza de los distintos paisajes, la diversa flora y fauna terrestre... Dada la temática del producto, destacan las imágenes de los fondos marinos como La isla del Diablo, las cavidades de las rocas submarinas, llamadas Los ojos de 
Neptuno; las cuevas misteriosas de Blue Hold, en la barrera de coral australiana; o el lago de las medusas.

La serie plantea un contenido heterogéneo. Esta variedad puede observarse en la organización interna de los capítulos y, sobre todo, en el metraje destinado a las diferentes temáticas. De los casi veinticuatro minutos que duran cada episodio, aproximadamente la mitad de la misma - una media de entre 11 minutos y medio y 13 minutos- son grabaciones del fondo del mar aunque esta proporción varía en función de la zona.

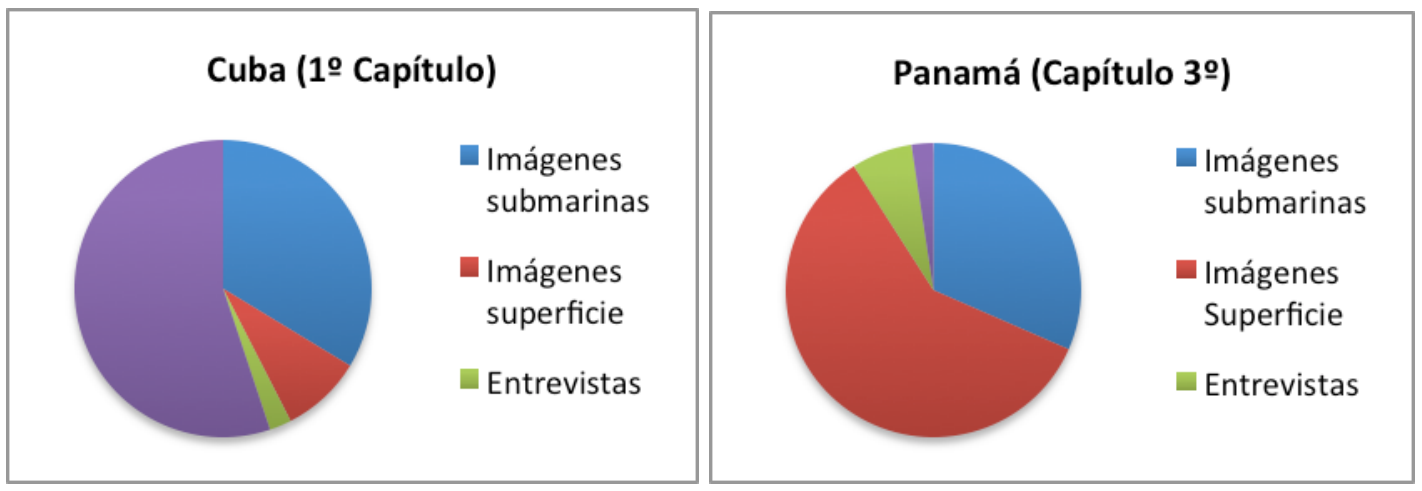

Fuente gráfico: Elaboración propia

Fuente gráfico: Elaboración propia

Como puede observarse en los gráficos, la diferencia entre unos episodios y otros es sustancial. Mientras que en Cuba predominan las imágenes acuáticas, en Panamá, por ejemplo, se priorizan los exteriores centrándose principalmente en la penitenciaria de la isla de Coiba - uno de los principales reclamos de la zona- a la que se le dedica casi cinco minutos de una duración total de veintidós minutos y cuarenta y cinco segundos.

Como muestra el caso de Panamá, las imágenes del exterior responden a dos vertientes diferentes de una misma cuestión, las posibilidades turísticas del destino. Por un lado se enseñan los lugares más conocidos de la zona a través del estereotipo. Esto puede observarse en el capítulo de Costa Rica (Capítulo 90) donde, bajo el lema de «Pura vida«, se presentan las singularidades del país -el Quetzal, diversidad de anfibios, especialmente la rana arlequín, las orquídeas...- de igual manera que en cualquier producto turístico. Por otro lado, se descubren hoteles y alojamientos curiosos y paradisíacos haciendo mucho hincapié en su condición de lugares remotos y bonitos. La mayor parte de estos complejos pertenecen o están regentados por europeos en busca de tranquilidad y exotismo.

La serie incorpora algunas herramientas propias del cine documental como, por ejemplo las entrevistas a expertos, grabadas en el tradicional formato de "busto parlante". La duración de las intervenciones oscila entre los veinte y los cincuenta segundos. Los entrevistados presentan diversos perfiles predominando de forma notable la presencia de dueños de 
hoteles o barcos y de instructores de buceo, cuestión que incide en el público potencial al que parece estar destinada la serie: amantes del buceo y de los viajes exóticos.

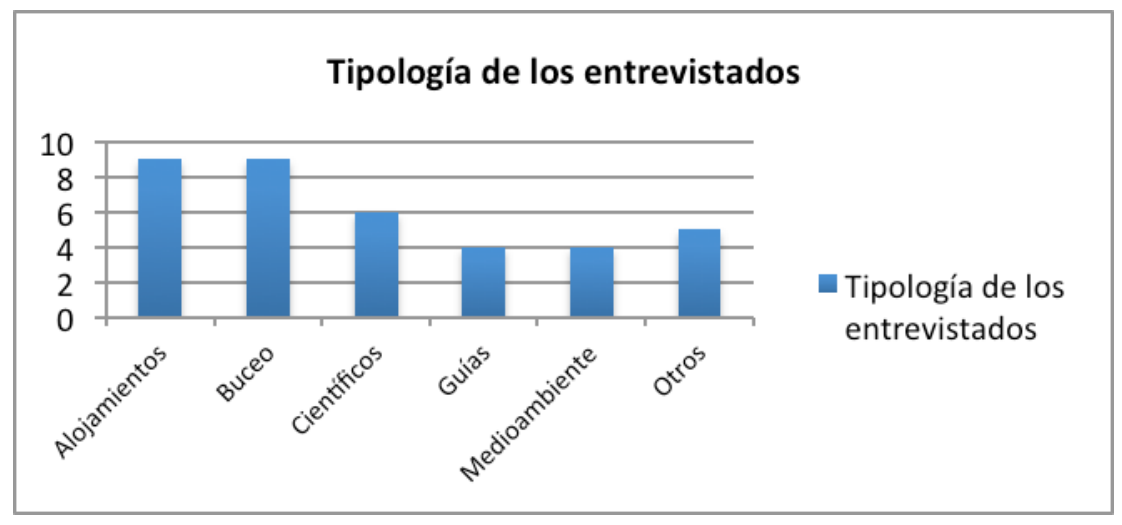

Fuente: Elaboración propia

Los principales temas de los que hablan los expertos son: la singularidad y belleza de las zonas: dueños de alojamientos, guías, instructores de buceo...; mientras que los problemas que acechan al ecosistema visitado son tratados por científicos y encargados de los Centros de estudios medioambientales.

Este marcado punto de vista es reforzado visualmente a través de la incesante presencia humana en las imágenes submarinas. Los buzos, principalmente la realizadora del documental -su imagen aparece, como media, en más de la mitad del metraje grabado- son quienes dirigen la mirada del espectador hacia aquello que debe ver. Esto se consigue a través de la construcción de las secuencias que, por lo general, pasan de un plano general en el que se encuadra algún miembro de la expedición a planos medios o primeros planos de los animales observados. Este tipo de montaje permite la interrelación del público con el individuo, un testigo de lo acontecido, a través del cual se produce la percepción de los fondos marinos.

Seaway platea sustanciales diferencia visuales entre las secuencias rodadas en la superficie y las grabadas en los fondos marinos. Los planos que conforman las primeras, especialmente aquellas que han sido tomados en las ciudades, son mucho más cortos que los rodados dentro del mar. En las escenas de ciudad, donde predominan los travelling y los planos generales y medios algunas veces en contrapicado, llegan incluso a durar menos de un segundo. En todas se observan calles con coches, edificios muy altos y mucha presencia humana. La corta duración de los planos su angulación y el montaje rápido y al corte, marca un ritmo acelerado claramente intencional que busca generar en el espectador la idea de bullicio y de prisa. La cadencia de las imágenes se va atenuando a medida que la expedición se adentra en territorios más naturales. En ellos, las escenas se hacen más largas deteniéndose con primeros planos y planos detalles en los elementos más interesantes. Las 
playas y los lugares de descanso se muestran casi siempre vacíos y cuando se muestran seres humanos aparecen en grupos pequeños y con actitudes relajadas.

En el mar el montaje es mucho más tranquilo. Esto puede observarse tanto en la duración de las secuencias que suelen alargarse de media hasta los 8 segundos como en los fundidos entre las diferentes imágenes que permiten la transición de una a otra. Ambas cuestiones, unidas a los suaves movimientos de la cámara están pensadas para crear en el espectador la impresión de estar dentro de los fondos mecidos por las corrientes algo que genera una sensación de paz y tranquilidad. En ningún caso, salvo las escenas provocadas por los instructores en las que se da de comer a los tiburones, se ruedan imágenes violentas. La ausencia de elementos agresivos junto a la elección de planos amables muestran unos fondos marinos donde los diferentes animales si bien no parecen interactuar demasiado entre ellos, conviven de forma absolutamente pacífica. Los peligros que parece acecharles son exógenos y, generalmente, motivados por los humanos. Esta cuestión está claramente potenciada por el elementos sonoros utilizados.

La música que introduce la serie Seaway, compuesta por Kaelo del Río, es utilizada no solo como ambientación, sino también, como un medio expresivo más. Así, la cualidad musical a la que más ha recurrido en todos los capítulos es a la llamada música subjetiva. Este tipo de música les ha proporcionado una mejor expresión del contenido de la serie y un apoyo extraordinario a las situaciones emocionales concretas. Su objetivo es crear en las inmersiones acuáticas un ambiente marino que potencie las imágenes y las locuciones.

Un claro ejemplo aparece en el capítulo $1^{\circ}$ (Cuba), donde los preparativos de la inmersión carecen de apoyo musical -solo tienen sonido ambiente- mientras que en las escenas bajo el agua se acompañan de una música relajante, casi hipnótica. Todas las músicas de las inmersiones son acordes al movimiento visual, es decir a cómo discurren las imágenes, tanto por su montaje o sucesión de los planos como por los movimientos de la cámara y la acción de los "personajes" marinos. En este sentido, las músicas subjetivas corresponden perfectamente al estado anímico que pretenden trasladar los autores.

Las situaciones emocionales que presenta cada episodio requieren de una ilustración musical muy precisa ya que desempeña una función interpretadora, pero es interesante comprobar cómo el compositor no es reiterativo, no duplica aquello que por su imagen y locución nos es ya preciso y concreto.

Así, en el 90\% de los trece capítulos que forman la serie Seaway, apenas se utiliza el golpe musical, es decir, la entrada yuxtapuesta de un fragmento musical de cierto efectismo, mientras que sí predomina el encadenado musical, el tránsito suave de una música a otra, sin brusquedad. La gran profusión de primeros planos y planos medios, hace obligado que la música sea íntima y relajante. Por su parte, la palabra en off no tiende a producir picos de onda muy marcadas; al contrario, son locuciones más bien planas, por lo que, la música va 
en la misma línea apoyándose en notas largas y sin ninguna percusión sobresaliente, de aquí su empaste efectivo.

Trato aparte merece la sintonía, llama la atención desde sus primeras notas y su sentido expresivo logra causar un impacto en el telespectador. Es original, rítmica, melódica y tímbrica, dando sensación de modernidad y dinamismo. Su duración es proporcionada a la duración del capítulo: la cabecera tiene una duración de 42 segundos y la versión larga para los créditos finales de 80 segundos de los 25 minutos que dura cada capítulo.

Es de resaltar la huida de Kaelos del Río de ideas manidas o convencionales, decantándose por una ambientación sonora con elementos creativos $\mathrm{y}$ originales $\mathrm{y}$ dentro de las posibilidades que marca la línea de esta serie documental.

La serie presenta dos locuciones. Una masculina para la versión inglesa y otra, femenina para la española. Esta última, en la que se ha centrado el análisis, es llevada a cabo por Mónica González, directora y guionista de la serie, además de coprotagonista en todos los capítulos.

Según Dewhurst-Maddock (1993), la voz es el reflejo de nuestro estado mental, emocional y físico. Por ello es lógico que la locutora pretenda expresar a través de sus palabras las emociones que su cuerpo y su mente registraron en esos lugares.

Para la introducirlos utiliza frases más largas y hace una lectura más fluida que para el resto del capítulo. Por el contrario, en las imágenes subacuáticas predominan las frases cortas, líricas y de inflexiones planas.

En el capítulo $4^{\circ}$ (Indonesia) se puede apreciar abiertamente como utiliza la textura de las palabras. Sus locuciones tienen siempre un color y una textura concreta: la lírica, expresando la voz el contenido de la palabra. Este estilo conlleva una voz íntima, de reflexión interior en un intento de empatizar con el telespectador. Es, en definitiva, una locución claramente subjetiva a pesar de que apenas se empleen cambios de tono o microtonos.

Pero, ¿cómo es posible esto? En este capítulo, las locuciones de las inmersiones tienen una media de 68 palabras por minuto, divididas en frases entre 8 y 13 palabras. Esto quiere decir que utiliza frases cortas, por lo que las curvas de entonación no tienen suficiente tiempo de recorrido para articular melodías variadas y atractivas. Aquí los perfiles altos y bajos son muy poco relevantes. 


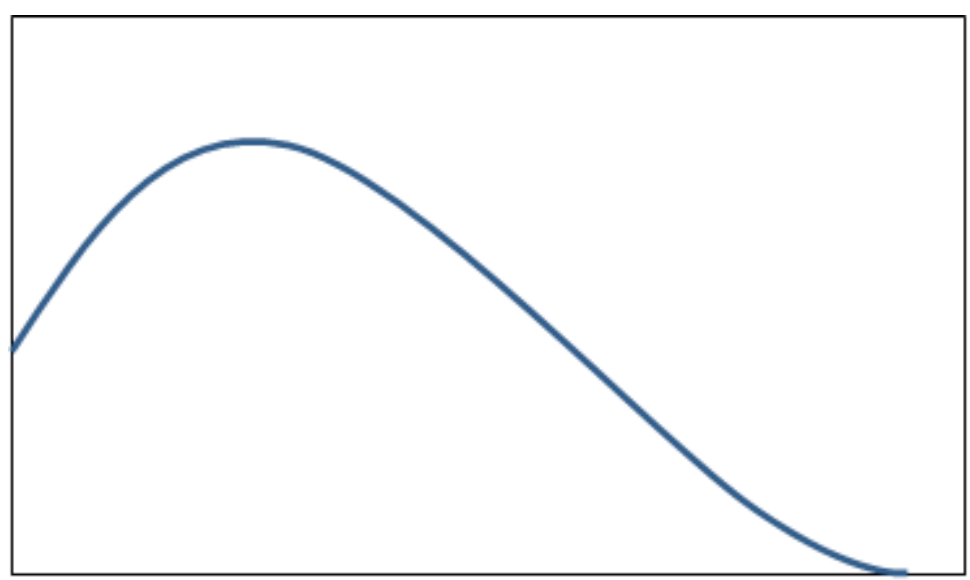

Representación de la curva de entonación más utilizada a lo largo de la locución. Fuente: Elaboración propia.

Si añadimos a esto el excesivo, y a veces erróneo, énfasis puesto en cada frase, conlleva que su expresividad sea plana. Cae en el error común de marcar todas las palabras del guion, sin apenas discriminar cuáles son las verdaderamente importantes. Esto provoca una locución poco natural y difícil de descodificar porque el telespectador acaba por no saber lo que se quiere destacar. Tampoco ayuda el que se alargue la pronunciación de palabras, restando naturalidad al relato o que, como hemos dicho, se enfaticen palabras que no son relevantes.

Veamos un ejemplo del capítulo 9 (Costa Rica):

"Este mero azul /nos mira de cerca. //Sus colores son/ muy vistosos" ${ }^{2}$ Se pueden apreciar claramente las limitaciones de una voz no profesional.

La locución en off de toda la serie debería parecer más hablada, no leída; más ilustrativa y no tan retórica, para mantener así esa imprescindible relación con la imagen. De igual modo, deberían respetarse más las pausas, e incluso alargar los silencios, para permitir que el telespectador descodifique los otros sonidos inherentes a las imágenes.

\section{Conclusiones}

La serie documental Seaway recorre algunos de los más bellos ecosistemas marinos del planeta. Pese a que, en principio, no se indica un target concreto, lo cierto es que la finalidad del formato -descubrir las zonas de buceo más peculiares y alejadas de los circuitos más comerciales así como las instalaciones turísticas existentes en las mismas- evidencia un público objetivo con unos intereses muy concreto.

Este propósito, de plasmar lo recóndito y exclusivo, es el principal rasgo de espectacularización de la serie, al servicio del cuál, se podrán las herramientas narrativas,

${ }^{2}$ Subrayamos la palabra en donde marca el énfasis. / pausa corta, // pausa larga 
sonoras y visuales. Sin embargo, estos destinos no solo destacan por su lejanía, también lo hacen por sus hermosos paisajes, otro de los elementos más relevantes de estos documentales. Las imágenes, muy cuidadas y de gran calidad, tiene como única misión deleitar. El programa se aleja de la función científica para crear -y recrear- una atmósfera muy concreta que pretende de cautivar al observador. Para ello, se ayuda no solo de la belleza de las imágenes sino, también, de un montaje muy concreto $y$, sobre todo, de un acompañamiento musical que potencia y corrobora el mensaje verbal y visual. El uso estilístico y emotivo de estos recursos es otro de los mecanismos tradicionalmente utilizados por la televisión espectáculo.

Seaway utiliza muchas de las herramientas narrativas del documental de naturaleza como la elección de especies por su belleza y peculiaridad o la antropomorfización de sus comportamientos aunque frente a este tipo de formatos no abusa de la dramatización abordando la presentación de animales y plantas desde un planteamiento poético que alude directamente a la emotividad del espectador.

Éste descubre aquello que solo unos pocos han visto a través de la realizadora-guionistapresentadora quien, focalizando la acción de forma absoluta, dirige su interés hacia los seres marinos descodificando sus actitudes, haciéndolos legibles.

La serie muestra una naturaleza amable, una especie de enorme jardín paradisíaco donde los animales conviven en armonía y en paz. Es especialmente relevante la casi ausencia de imágenes que muestran algún comportamiento agresivo entre diferentes especies. El único problema de los ecosistemas marítimos es el ser humano.

Su destrucción es uno de los temas recurrentes de la serie. En todos los episodios se menciona la situación de los fondos marinos señalando cuáles son los agentes más perniciosos - principalmente la contaminación o la pesca indiscriminada- y de qué manera pueden solventarse los problemas que estos generan. Un tema muy interesante y sugestivo dada su actualidad y el público potencial al que está destinada la serie.

\section{REFERENCIAS BIBLIOGRÁFICAS}

AUMONT, Jacques y MARIE, Michel (1988): Análisis del film. Barcelona. Paidós.

BAGUST, Phil (2008): «Sceen nature: special effect and edutainment in new hybrid wildlife documentary», Continuus: Journal of media \& cultural studies, vol 22, no 2, pp. 213226.

BIENVENIDO, León (2001): "Divulgación científica y documental televisivo. Estudio de las obras de David Attenboroughv", Treballs de la Societat Catalana de Biologia, vol. 51, pp. 253-266. 
CABEZA, José y MATEOS, Javier (2013): "Thinking about televisión audiences: Entertainment and reconstruction in nature documentaries" European Journal of Communication, vol 28, no 5, pp. 570-583.

CASETTI, Francesco y DI CHIO, Federico (1991): Cómo se analiza un film. Barcelona. Paidós.

DEWHURST-MADDOCK, Oliveas (1993): El libro de la terapia del sonido: cómo curarse con la música y la voz. Madrid. Edaf.

KING, Margaret (1996): "The audience of wilderness: the Disney nature films", Journal of popular film and Television, vol 24, issue 2, pp. 60-68

PARSONS, Christopher (1982): True to nature. Looks back on 25 years of wildlife filming with the BBC natural history unit. Cambridge, PSL.

SALCEDO, Miriam (2009): "El antropomorfismo como herramienta de divulgación científica por televisión: Estudio de El hombre y la tierra", Comunicación y sociedad, vol XXIV, $n \circ 1,217-246$.

SCOTT, Karen (2003): "The role of spectacle in Contemporary wildlife documentary" Journal of popular film and Television, vol 31 issue 1, pp. 60-68.

SCOTT, Karen (2006): "Unnatural History? Deconstructing the walking with dinosaurs phenomen", Media, Culture and Society, no 15, pp. 131-152.

SILVERSTONE, Roger (1985): Framing science: the making of a BBC documentary. Londres. BFI.

[Recibido: 30 de noviembre de 2015. Aceptado: 28 de enero de 2016] 